\title{
A new catalogue of observations of the eight major satellites of Saturn $(1874-2007)^{\star}$
}

\author{
J. Desmars ${ }^{1}$, A. Vienne ${ }^{1,2}$, and J.-E. Arlot ${ }^{1}$ \\ ${ }^{1}$ Institut de Mécanique Céleste et de Calcul des Éphémérides - Observatoire de Paris, UMR 8028 CNRS, \\ 77 avenue Denfert-Rochereau, 75014 Paris, France \\ e-mail: desmars@imcce.fr \\ ${ }^{2}$ LAL - Université de Lille, 59000 Lille, France
}

Received 15 May 2008 / Accepted 2 September 2008

\section{ABSTRACT}

\begin{abstract}
Context. The lastest catalogue of observations includes about 51000 observations (over 3500 nights) of Saturn's satellites from 1874 to 1989. Since 1989, many observations have been published, often in different formats, based on the publication.

Aims. Our new catalogue of observations of the eight major satellites of Saturn includes the observations of the previous catalogues, newly published data and also old observations left out of the previous catalogue. The observations are tabulated in a consistent format.

Methods. We give, for each observation, the corrections applied for reduction such as refraction, aberration or phase effects. Furthermore, when it was possible, the instrument and catalogue are also indicated.

Results. The new catalogue presents more than 130000 observations (over 6000 nights) of the eight major satellites of Saturn from 1874 to 2007.
\end{abstract}

Key words. catalogs - planets and satellites: individual: Saturn - astrometry

\section{Introduction}

The improvement of natural satellite ephemerides and the knowledge of their dynamical motion are required to fit dynamical models to observations.

Since the publication of the Strugnell \& Taylor catalogue ST90 (1990) and the Harper \& Taylor extension HT94 (1994) which tabulate in total about 67000 observations of Saturn's satellites, many other observations have been realized and published. Our aim is to extend these catalogues by adding new and also old observations that previously have been ignored. We call the new catalogue COSS08 for Catalogue of Observations of Saturnian Satellites, and 08 because it is the 2008 version of the catalogue. We plan to update the catalogue with new observations in the future.

Although Saturn's satellites have been observed since the 17th century, the oldest observations of COSS08 come from USNO in 1874. The most recent ones come from Flagstaff in early 2007. During this long period (more than 130 years) many observations have been carried out by many different observers publishing their data in different formats. To compare observations with theoretical positions, all these observations have to be tabulated in a single and consistent format. The same format as the ST90 catalogue has been used as a basis, and other parameters have been added.

\footnotetext{
* The catalogue is available in electronic form at the CDS via anonymous ftp to cdsarc.u-strasbg. fr $(130.79 .128 .5)$ or via http://cdsweb.u-strasbg.fr/cgi-bin/qcat?]/A+A/493/1183
}

\section{The observations}

The first Saturnian satellites were discovered in the second part of the 17th century by Huygens (for Titan) and by Cassini (for Tethys, Dione, Rhea ans Iapetus). Mimas and Enceladus were discovered more than one century later by Herschel in 1789 . Hyperion was discovered by Bond and Lassell in 1848. Since their discovery, Saturn's satellites have been observed to better understand their motion. Observations of satellites can be classified in seven different types:

- timing of elongation, opposition and conjunction;

- visual micrometer measures;

- photographic astrometric measures;

- automatic meridian transit circle measures;

- CCD image measures;

- photometry of mutual events;

- HST observations.

The first six ones (ground-based observations) are explained and detailed in HT94. In the last one, observations are from the Hubble Space Telescope (French et al. 2006). A first datacollection of observations was made by Pierce (1975) who tabulated observations of Saturn's satellites from 1789 to 1972. Consistent Harper \& Taylor (1994), our catalogue does not deal with timings of elongation, opposition and conjunction made in the late 18th and in the 19th century, because they are few in number and low in accuracy. Furthermore, these observations are very specific, appearing to be specific events. So, their reduction in position is particular and will be the object of a forthcoming paper. The period of the catalogue stretches from 1874 to 2007.

COSS08 is a compilation of four different sources of observations. The first two are observations from ST90 and HT94. 
The large part of the added observations comes from the Natural Satellites Data Center NSDC (Emelianov \& Arlot 2005). Some recent observations also have been tabulated in COSS08.

\subsection{The Strugnell \& Taylor catalogue (Ref. Code 1-61)}

ST90 is made up of 51000 observations (over 3500 nights) of the eight major satellites of Saturn. The observations from 1874 to 1989 are tabulated in a consistent format. We use the same format but we add new parameters (see Sect. 4). Moreover, the Reference Code used in ST90 has been kept. This code characterizes each bibliographic reference and each instrument used by giving reference. Thus, in a few cases, when different instruments have been used in a reference, this reference can present different Reference Code numbers.

A brief history and description of those observations of Saturn's satellites can be found in ST90.

As we will see (see Sect. 2.3), some observations of ST90 have been reduced again since the catalogue's publication. New reduced data have been favoured in COSS08 because of their better accuracy.

Among these observations, the Tolbin ones (Ref. Code 30 in ST90) have been reduced again (Tolbin 1991b). The new reduced positions replace the initial ones in COSS08 (Ref. Code 510). Likewise, the Tolbin observations (Ref. Code 33 in ST90) are replaced in COSS08 by the observations that have been reduced again (Tolbin 1991a) (Ref. Code 511).

In ST90, some groups of observations have not been published, for example, observations from Veillet and Dourneau, and from Pascu. The first ones have been published in Veillet \& Dourneau (1992), but the Pascu ones still have not been published. Request for these data must be made to the author.

A longitude discrepancy due to phase effects has been detected by Aksnes et al. (1986) in mutual phenomena observations of the Galilean satellites of Jupiter in 1973 and of the Saturnian satellites in 1980. They proposed corrections to these observations (Aksnes et al. 1984) that we have taken into account in COSS08 for the Saturnian satellite observations.

\subsection{The Harper \& Taylor catalogue (Ref. Code 101-243)}

Harper \& Taylor (HT94) have compilated over 15000 new ground-based observations of the major satellites of Saturn in order to fit analytical theory to the observations. They used an extended version of the Strugnell \& Taylor catalogue. This includes observations made at the Lick, Yerkes and Leander McCormick observatories between 1894 and 1922. Most of those observations are visual micrometer measures.

\subsection{The NSDC database (Ref. Code 420-552)}

The Natural Satellites Data Center (Emelianov \& Arlot 2005) provides data on natural planetary satellites (except the Moon). On the NSDC web site ${ }^{1}$, each group of observations is published in its original format. A file gives information about time scale, reference system, reference frame, observation type, instrument used and sometimes catalogue reference and corrections (aberration, refraction, etc.) for reduction.

In the nomenclature of NSDC files, the rule for the Reference Code is as following: observations in the file called sm00XX on the NSDC web site will have Ref. Code 5XX in COSS08. For example, observations in Debehogne (1979) appear in file sm0004

\footnotetext{
1 Available at the adress http://www . imcce. fr/nsdc
}

on the NSDC web site. Then the Ref. Code of those observations is 504 in COSS08. Observations in Noyelles et al. (2003) are the single exception to the rule, because we kept the distinction between best observations (Ref. Code 420) and acceptable observations (Ref. Code 421).

When a CCD camera has been used, most observations are given in raw data. This means that the satellite positions are given in intersatellite coordinates and in pixels units. These data can be expressed in classical units (arcsec) with a scale factor and the orientation of the receptor (see Harper et al. 1997, for more details).

For observations in Harper et al. (1997, 1999), Vienne et al. (2001a), Peng et al. (2002) and Veiga et al. (2003), satellites were observed on the CCD images and their coordinates given in relation to an arbitrary origin, the CCD image center. To express the satellite positions, we make a choice between observed satellite and reference satellite. This choice for the reference satellite is in the order: Rhea, Titan, Dione, Tethys, Enceladus, Mimas, Hyperion, Iapetus. For example, if Enceladus, Dione, Titan and Iapetus were observed on the same CCD image, three observations are given in our catalogue: Iapetus-Titan, EnceladusTitan and Dione-Titan ${ }^{2}$. This choice is related to the accuracy of the ephemerides of each satellite. For example, Titan and Rhea have better known orbits than Mimas, Iapetus or Hyperion. Also, Rhea has been more observed than Titan.

As we saw in Sect. 2.1, some observations of ST90 have been reduced again since the publication of the catalogue. Observations from the Nikolaev observatory published in ST90 were reduced again and published in Voronenko et al. (1991, sm0037 file on the NSDC web site), likewise for observations in Voronenko \& Gorel (1988). Thus, observations from the Nikolaev observatory have been deleted and replaced by Voronenko et al. (1991) data (now with Ref. Code 537 in COSS08).

Some NSDC data are redundant, for example, observations in Izmailov (1998, sm0015) and ones in Kisseleva \& Izmailov (2000) (sm0030). We keep only observations from Kisseleva \& Izmailov (Ref. Code 530) because they have been reduced again compared to Izmailov ones.

Likewise, observations in Kisseleva \& Chanturiya (2000) are given in absolute coordinates $(\alpha, \delta)$ in file sm0025 and in intersatellite coordinates compared to Titan in sm0026. In that case, we favour observations in absolute coordinates because they allow us to have an additional coordinate of Titan (Ref. Code 525).

For files sm0027 (absolute coordinates) and sm0028 (intersatellite positions relative to Titan) which present observations of Hyperion only, we have preferred the absolute coordinates to the intersatellite positions. Indeed, the date of observations in sm0027 are the same in the sm0025 file. This is why we have kept observations in sm0027 but have allocated the Ref. Code 525.

In the particular case of the observations of Kiseleva et al. (1996, sm0013 and sm0014 files with positions relative to the planet and Titan) and in Kiseleva \& Kalinitchenko (2000, sm0029 file), as several of them are redundant, we present in COSS08 the positions relative to the planet when more than two satellites were observed at the same time. If only one satellite was observed, we preferred the intersatellite positions relative to another satellite.

Finally, some observations in Vienne (2001a) are redundant. In that case, the CCD image with the largest number of satellites were favoured. If we have two CCD images with

\footnotetext{
2 With the notation observed satellite-reference satellite.
} 
the same number of satellites, the one with the best $\mathrm{O}-\mathrm{C}$ was favoured. Likewise for some observations in Vass (1997) which are redundant.

\subsection{The recent observations (Ref. Code 600-608)}

Recent observations represent more than 9900 new data points. They have been obtained or published during the period 1994-2007.

Qiao et al. (1999) present 451 measurements of positions of Saturn's satellites made from 1994 to 1996 and Qiao et al. (2004) present 1167 new measurements. All these observations were made using a CCD detector attached to the $1.56 \mathrm{~m}$ reflector at the Sheshan Station in China.

The NOFS observations (USNO) from Flagstaff were obtained from 2000 to 2007 and have been usually updated. The last update was done on April 18th 2007. The first observations from 2000 to March 2001 were published in Stone (2001). So, those of NOFS have been excluded and those in Stone kept. All data are available on the web site of the FASTT Planetary Satellite Observations http://www. nofs. navy.mil/data/plansat.html.

French et al. (2006) published highly accurate astrometric positions of Saturn's satellites. Positions were obtained with Hubble Space Telescope between 1996 and 2005. Some satellite positions were measured in Planetary Camera frames (Ref. Code 605) and others in Wide Field (WF) frames (Ref. Code 606 for WF2, 607 for WF3 and 608 for WF4).

Rapaport et al. (2002) use CCD meridian circle observations for positions of Dione, Rhea, Titan, Hyperion and Iapetus. Those observations were made at the Bordeaux observatory from 1995 to 2001 .

The same instrument was used for the observations of Dourneau et al. (2007). 216 observations of Titan, Hyperion and Iapetus were made between 1999 and 2007 (available at: ftp://ftp.imcce.fr/pub/misc/bordeaux/ 1995-2007/). Some of them were published in Rapaport et al. (2002) and so are excluded from this database.

\subsection{Instrument and catalogue of stars}

In Table 2, we indicate for each Reference Code the corresponding bibliographic reference, observatory and instrument used. Refractors with many different diameters are generally used. Nevertheless, reflectors, meridian circle and astrographs are also used.

For added observations (NSDC and recent observations) and when it was possible, the catalogue of reference stars (like PPM, ACT, AST, Tycho,...) used for the reduction is given. Several methods of astrometric reduction without reference stars have been developed. In such a case, calibration is made using a dynamical theory and well known satellites. For example, in Veiga et al. (2003), dynamical model TASS1.7 (Vienne \& Duriez 1994) and satellites Tethys (S3), Dione (S4), Rhea (S5) and Titan (S6) were used to calibrate the CCD frame. So we note S3-S4S5-S6 TASS1.7 as the reference star catalogue in Table 3. Qiao et al. (1999) used differents dynamical models for the calibration. In Table 3, HT93 refers to Harper \& Taylor (1993), TS88 refers to Taylor \& Shen (1988) and D87 refers to Dourneau (1987).

French et al. (2006) used the rings (especially the Encke division) for the calibration. Veillet \& Dourneau (1992,
Ref. Code 47) used the satellites S2-S3-S4-S5-S6 with the Dourneau theory (Dourneau 1987) for calibration.

\section{Corrections of the reduction}

One of the interests of an astrometric observation catalogue is the comparison between the dynamical model of satellite motions and observations. Thus, we have to apply some corrections like time scale, light-time, aberration, refraction and phase effects. Because some effects are not very important (less than $\left.0.2^{\prime \prime}\right)$, these astrometric corrections were not automatically taken into account before now. While we present in this paper the main corrections, more details about effects can be found in Vienne et al. (2001a).

\subsection{Time scale}

To compute astrometrical residuals of observations, we need to have the same time scale. Usually, the time scale for dynamical models is the terrestrial time (TT) and observations are given in Universal Coordinate Time (UTC). The difference between TT and UTC (given by d $t$ parameter in COSS08) can be determined since 1972 with the relation between UTC, TT and TAI (Temps Atomique International): TT $=\mathrm{TAI}+32.184$ and the difference TAI-UTC is an integer number of seconds, which follows the Earth's rotation, fixed by the International Earth rotation and Reference systems Service (IERS). Before 1972, UTC was approximated by UT1 and we use the relation between UT1 and TAI given in Stephenson and Morrison (1984).

For all observations, the sum of $u t c$ and $\mathrm{d} t$ parameters (UTC and TT-UTC respectively, see Sect. 4.1) gives the time of observation in TT. In Hatanaka (1995), Rapaport (2000), Izakevich (2001) and in Carlsberg (1999), observations were given in TT. So for those observations, the UTC time given in COSS08 is determined with the parameter $\mathrm{d} t$ with $\mathrm{UTC}=\mathrm{TT}-\mathrm{d} t$.

Moreover, for one particular kind of observation (Kostinsky 1925), the time of observation is in a particular scale, MZ, corresponding to local time. In COSS08, this time is given in UTC from the relation between UTC and MZ for the Pulkovo observatory, $\mathrm{UTC}=\mathrm{MZ}+12 \mathrm{~h}-2 \mathrm{~h} 01 \mathrm{~m} 26 \mathrm{~s}$.

\subsection{Light-time correction}

The light-time is the difference between the time when the light leaves the observed object and the time when the light arrives at the observer. During the light-time $(\tau)$, the object moves on its orbit and then the observer measures the object's position not at time $t$ but at time $t-\tau$. The observation time is that of the arrival of the light signal at the observer. Consequently, no light time correction is made for observations.

\subsection{Refraction correction}

The position of ground-observed objects is modified by the atmosphere. In general, the atmospheric model assumes horizontal layers with equal refractive index. Refraction is the angle between observed zenith distance $z_{0}$ and zenith distance without atmosphere $z: R=z-z_{0}$. Many models of refraction have been developed. To compute astrometric residual observations when refraction has not been corrected by the observer, the Laplace formula with parameters deduced from the refraction tables of 
Pulkovo was used (Pulkovo 1985). With the Laplace formula, the refraction is a function of the observed zenith distance:

$R=\mathcal{A} \tan z_{0}-\mathcal{B} \tan ^{3} z_{0}$

where $\mathcal{A}$ and $\mathcal{B}$ depend on temperature, pressure and wavelength. For standard atmospheric conditions (temperature of $0{ }^{\circ} \mathrm{C}$, pressure of $1013 \mathrm{hPa}$ and wavelength of $590 \mathrm{~nm}$ ), the coefficients are $\mathcal{A}=60$ '.236 and $\mathcal{B}=0$ '.0675. Few observations (96 between 1875 and 1928) have been realized where the zenith distance was more than $70^{\circ}$. For such zenith distances the Laplace Formula is not very accurate. If the refraction has to be corrected, the parameter refrac is 2 or 3 . If the refraction has already been corrected, the parameter is 0 or 1 (see Sects. 3.6 and 4.1).

\subsection{Aberration correction}

Aberration is the result of two facts: the light velocity is finite and the observer is in motion compared to stars. While the light is traveling from the object to the observer on the moving Earth, the observer moves away from the position occupied in space at the instant the light left the object (Woolard \& Clemence 1966). To take into account aberration effects, we compute the position of the observer at time $t-\tau$ assuming that between $t-\tau$ and $t$, the Earth's motion is straight and uniform. In COSS08, if the parameter aberr indicates 0 or 1 , it means that aberration has already been corrected. In the opposite case (aberr $=2$ or 3$)$, the aberration has not been corrected (see Sects. 3.6 and 4.1).

\subsection{Phase effect correction}

Phase effects produce a shift between the photocenter (which is observed) and center of mass (which is computed). For Saturn, the phase angle can reach 6 degrees. Lindegren (1977) estimates the shift between photocenter and center of mass for a spherical and homogeneous object in relation to its radius and the phase angle. The maximum value of this shift reaches 14 mas for Titan and 4 mas for Rhea. The impact of the phase effect can be debated for satellites like Mimas or Iapetus because of their inhomogeneous surfaces. Lindegren's method is only used to compute our own residuals presented in COSS08, when it appears necessary. If the phase effect has to be taken into account, the parameter phase indicates 2 or 3 , and 0 or 1 in the opposite case (see Sects. 3.6 and 4.1).

\subsection{Rules for corrections}

The main problem when computing the $\mathrm{O}-\mathrm{C}$ is to know if corrections have already been taken into account in the data publication. Sometimes, information about the reduction is given in a publication. But most of the time, this information is partially or totally missing, especially for observations before 1950. In this period, observations were not very accurate and the effects induced by refraction or aberration were smaller than the accuracy of those observations. However, information about corrections is also partially absent in recent publications.

Consistent with ST90, we correct refraction or aberration effects, if corrections are not explicilty stated, for observations before 1947 and we assume that observations after 1961 have already been corrected. This general rule nevertheless has many exceptions. To deal with suspicious observations, we compute $\mathrm{O}-\mathrm{C}$ by correcting effects and without correcting effects and we choose those with the smallest $\mathrm{O}-\mathrm{C}$.
In the catalogue, three parameters inform about the corrections (see Sect. 4.1). We give information about that choice by distinguishing four cases for correction. The first one $(0)$ is if the correction is clearly indicated in the publication. The second one (1) is when correction is presumedly made (either if the observation was made after 1961 or if the no-correction gives a better $\mathrm{O}-\mathrm{C}$ ). The third one (2) is when the correction is presumedly not made and the fourth one (3) is when no-correction is clearly indicated in the publication.

\subsection{The case of tangential coordinates}

With a photographic or CCD receptor, the satellites position are measured in the tangential plane of the celestial sphere at a point $\mathrm{C}\left(\alpha_{\mathrm{C}}, \delta_{\mathrm{C}}\right)$ which is generally the center of the frame. Local deformations induce a difference between the differential coordinates $\left(\Delta \alpha \cos \left(\delta_{\mathrm{C}}\right), \Delta \delta\right)$ and tangential coordinates $(X, Y)$ of a satellite's positions referred to C. If $\Delta \alpha$ and $\Delta \delta$ are small, the relation between these two types of coordinates is :

$X=\Delta \alpha \cos \delta_{\mathrm{C}}-\Delta \alpha \Delta \delta \sin \delta_{\mathrm{C}}+\ldots$

$Y=\Delta \delta+\frac{1}{2}(\Delta \alpha)^{2} \sin \delta_{\mathrm{C}} \cos \delta_{\mathrm{C}}+\ldots$

In the past, the accuracy of the observations was not high enough to take this difference into account. Nowadays, many observers still consider that $X=\Delta \alpha \cos \delta_{\mathrm{C}}$ and $Y=\Delta \delta$.

Vienne et al. (2001b) evaluate that the difference $(X-$ $\Delta \alpha \cos \delta_{\mathrm{C}}, Y-\Delta \delta$ ) is about $s^{2} \tan \delta_{\mathrm{C}}$ (where $s$ is the separation angle). They estimate the maximum value as $0.3^{\prime \prime}$ for extreme conditions $s=400^{\prime \prime}$ and $\delta_{\mathrm{C}}=23^{\circ}$. Nevertheless, this value is rarely reached and for example, the difference reaches $0.022^{\prime \prime}$ for observations of Harper et al. (1997) and 0.004" for Vienne et al. (2001a) because Saturn is near the equator. Moreover, when the field is small, the difference is negligible.

To test this, we have computed residuals by considering that observations in differential coordinates (typ $=1$ ) were given in tangential coordinates and we compared results. It appears that some observations (for example Kiseleva et al. 1996, Ref. Code 513) have better residuals if they are considered as tangential residuals. We have also verified that the difference is negligible when the field is small or when no reference stars are available (see Sect. 2.5).

Normally, the difference has to be taken into account but, because we do not know how the observers make the reduction, we can just use the type of coordinates they published even if they are incorrect. Moreover, to use the tangential coordinates, we need to give the position of the center of the frame which is rarely available. Consequently, in COSS08, there are no obervations in tangential coordinates. But we warn readers that some observations in differentials coordinates could be in tangential coordinates.

\section{The catalogue}

\subsection{The format}

The COSS08 observations are tabulated in chronological order and in a consistent format. An example extracted from COSS08 can be seen in Table 4. The full COSS08 catalogue is available in electronic form via anonymous ftp to cdsarc.u-strasbg. fr or via http://cdsweb.u-strasbg.fr/ or on the web server of the IMCCE (see address in acknowledgements). In a 
FORTRAN code, one line is read with the format:

(i3 $, \mathrm{i} 5, \mathrm{i} 3, \mathrm{f} 11.7, \mathrm{f} 7.3, \mathrm{a} 4, \mathrm{i} 4, \mathrm{i} 2, \mathrm{i3}, \mathrm{a} 1, \mathrm{i} 2, \mathrm{i} 1,2 \mathrm{f} 14.7$, $2 i 2,2 f 8.3,4 i 2$ )

The meaning of each parameter is:

- opp (i3): number of opposition $(1=1610,257=1874$, $385=2007)$

- $\operatorname{anp}(\mathrm{i} 5)$ : year of observation

- moi (i3): month of observation

- utc (f11.7): UTC time of observation in days (without lighttime correction)

- $\mathrm{d} t(\mathrm{f} 7.3)$ : TT-UTC in seconds

- $c o b$ (a4): observatory code (IAU) from Minor Planet Center ${ }^{3}$

- $\operatorname{crf}$ (i4): reference code (see Sect. 2.1 and Table 2)

- typ (i2): observation type

. $0=\alpha, \delta$

$1=\Delta \alpha \cos (\delta), \Delta \delta$

. $2=\Delta \alpha, \Delta \delta$

$3=p, s$ (position angle, separation)

- $\operatorname{csob}$ (i3): observed satellite

- $\operatorname{csrf}(\mathrm{a} 1)$ : reference object

. * absolute coordinates

. $0=$ Saturn

. 1 = Mimas

. 2 = Enceladus

. $3=$ Tethys

$4=$ Dione

$5=$ Rhea

$6=$ Titan

. 7 = Hyperion

8 = Iapetus

- $f g 1$ (i2): presence flag for the first coordinate $(0=$ missing, $1=$ present)

- $f g 2$ (i1): presence flag for the second coordinate $(0=$ missing, $1=$ present $)$

- obl (f14.7): first coordinate $(0.0000000$ if presence flag $=$ $0)$

- ob2 (f14.7): second coordinate ${ }^{4}$

- rfs (i2): reference system

. $0=$ mean equator and equinox of B1950

. $1=$ true equator and equinox of date of the observation

. 2 = mean equator and equinox of J2000

. 3 = mean equator and equinox at the nearest beginning of a year

. 4 = mean equator and equinox at 1 January of the year of observation

- $r f r($ i2): reference frame

. $0=$ topocentric

. 1 = geocentric

$2=$ heliocentric

- ocl (f8.3): (O-C) residual for the first coordinate (999.999 if missing)

- oc2 (f8.3): (O-C) residual for the second coordinate (999.999 if missing)

- refrac (i2): refraction correction

. $0=$ corrected

. 1 = presumedly corrected

. $2=$ presumedly not corrected

. $3=$ not corrected

${ }^{3}$ Available at the adress:

http: //cfa-www . harvard. edu/iau/lists/ObsCodes.html

${ }^{4}$ Units are for typ $=0$ : degrees, typ $=1$ : seconds of degrees, typ $=2$ : (seconds of hour, seconds de degrees), typ $=3$ : (degrees, seconds of degrees).

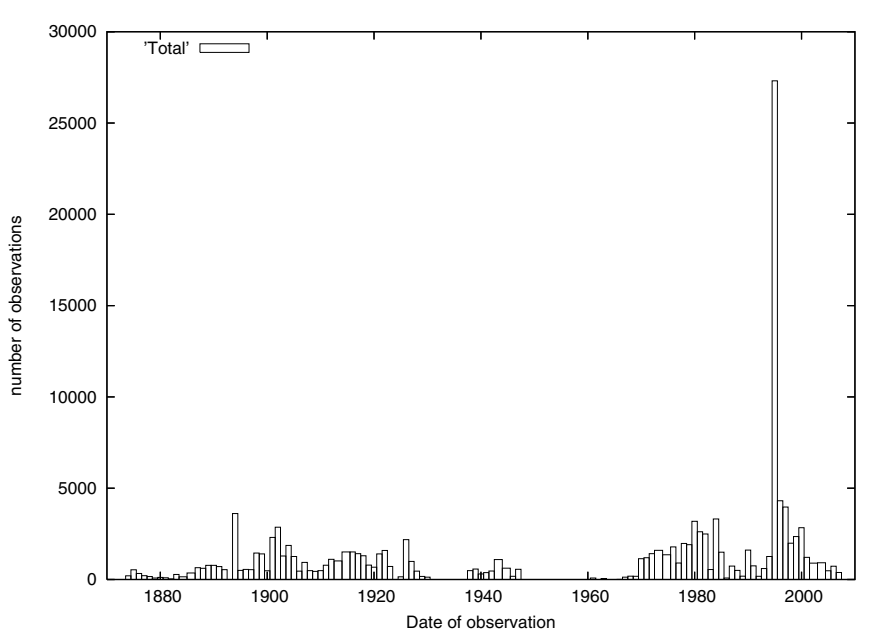

Fig. 1. Histogram of number of observations at each opposition.

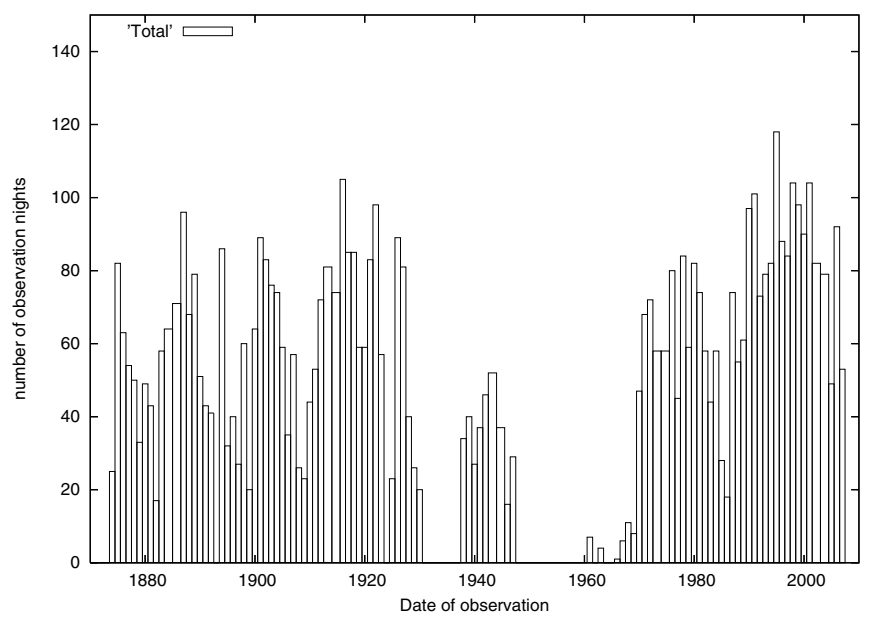

Fig. 2. Histogram of number of observation nights at each opposition.

Table 1. Number of observations, number of nights of observation and period covered for each satellite.

\begin{tabular}{crrc}
\hline \hline Satellite & Number & Nights & Covered period \\
\hline Mimas & 4410 & 714 & $1874-2005$ \\
Enceladus & 11529 & 1927 & $1874-2005$ \\
Tethys & 24034 & 3275 & $1874-2007$ \\
Dione & 21501 & 3265 & $1874-2007$ \\
Rhea & 26920 & 3976 & $1874-2007$ \\
Titan & 22788 & 4011 & $1874-2007$ \\
Hyperion & 7321 & 1896 & $1874-2007$ \\
Iapetus & 12395 & 2760 & $1874-2007$ \\
\hline
\end{tabular}

- aberr (i2): aberration correction

. $0=$ corrected

. 1 = presumedly corrected

. 2 = presumedly not corrected

. 3 = not corrected

- phase (i2): phase effects correction

. $0=$ corrected

. 1 = presumedly corrected

. 2 = presumedly notcorrected

. $3=$ not corrected

- satref (i2) (optional): reference satellite for O-C computation when a group of observations is given in absolute coordinates or compared to the planet at the same time. 

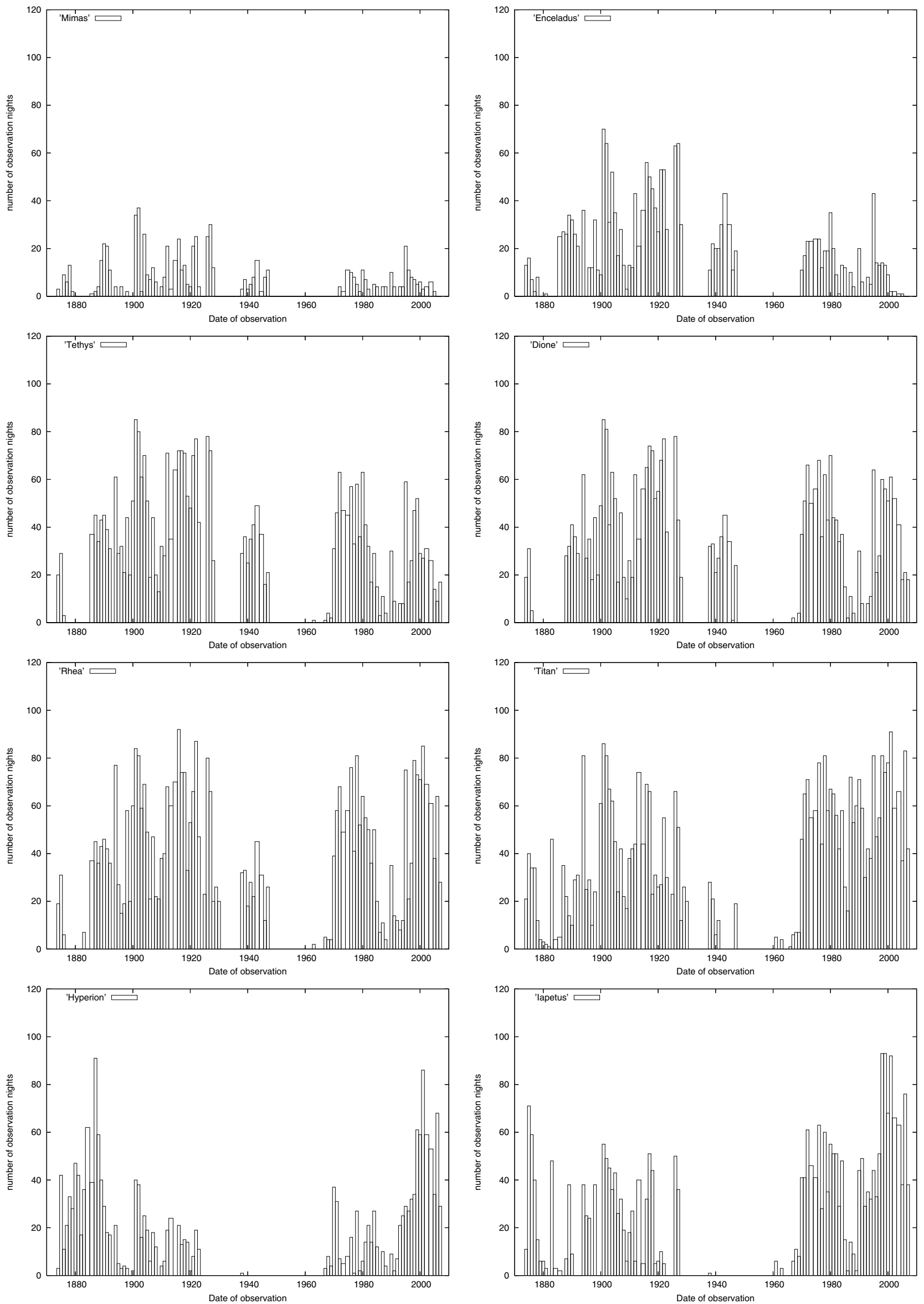

Fig. 3. Histogram of number of observation nights of each satellite at each opposition. 
Table 2. List of the observations of the first eight Saturnian satellites presented in COSS08.

\begin{tabular}{|c|c|c|c|}
\hline Ref. Code & Reference & Observatory & Instrument \\
\hline \multicolumn{4}{|c|}{ Strugnell $\mathcal{E}$ Taylor references } \\
\hline 1 & USNO (1877-1887) & USNO Washington (before 1893) & Telescope - refrac., $D=26$ inch \\
\hline 2 & USNO (1887, 1889-1893) & USNO Washington (before 1893) & Telescope - refrac., $D=26$ inch \\
\hline 3 & USNO (1911) & USNO Washington (since 1893) & Telescope - refrac., $D=26$ inch \\
\hline 4 & USNO (1929) & USNO Washington (since 1893) & Telescope - refrac., $D=26$ inch \\
\hline 5 & USNO (1954) & USNO Washington (since 1893) & Telescope - refrac., $D=26$ inch \\
\hline 6 & Struve (1933) & Berlin-Babelsberg & Telescope $-65-\mathrm{cm}$ refrac. \\
\hline 7 & Struve (1933) & Johannesburg & Telescope - 65-cm refrac. \\
\hline 8 & Struve (1933) & Yerkes Observatory & Telescope - 40-inch refrac. \\
\hline 9 & Struve (1898) & Pulkovo & Telescopes: 30-inch refrac. \\
\hline 10 & Alden \& O'Connell (1928) & Yale-Columbia Station & Telescope: 26 -inch photographic refrac. \\
\hline 11 & Alden (1929) & Yale-Columbia Station & Telescope: 26 -inch photographic refrac. \\
\hline 12 & Soulie \& Pourteau (1968) & Bordeaux-Floirac & Telescopes: $30 \mathrm{~cm}$ refrac. \\
\hline 13 & Chernykh \& Chernykh (1971) & Crimea-Simeis & Telescope - astrograph, $D=40 \mathrm{~cm}$ \\
\hline 14 & Soulie (1972) & Bordeaux-Floirac & Telescope: 13 -inch photographic refrac. \\
\hline 15 & Soulie (1975) & Bordeaux-Floirac & Telescope: $33-\mathrm{cm}$ refrac. \\
\hline 16 & Peters (1973) & Table Mountain Observatory & Telescope: 24-inch reflec. \\
\hline 17 & Soulie (1975) & Bordeaux-Floirac & Telescope: 38-cm refrac. \\
\hline 18 & Kisseleva et al. (1977) & Pulkovo & Telescope: 26-inch refrac. \\
\hline 19 & Kisseleva et al. (1977) & Pulkovo & Telescope: normal astrograph \\
\hline 20 & Kisseleva et al. (1977) & Pulkovo & Telescopes: AKD (double short-focus astrograph) \\
\hline 21 & Abbot et al. (1975) & McDonald Observatory & $\begin{array}{l}\text { Telescopes: } 2.1 \mathrm{~m} \text { reflec., } 76 \mathrm{~cm} \text { reflec. } \\
\text { Meas.machine: Mann measures }\end{array}$ \\
\hline 22 & Abbot et al(1975) & McDonald Observatory & $\begin{array}{l}\text { Telescopes: } 2.1 \mathrm{~m} \text { reflec., } 76 \mathrm{~cm} \text { reflec. } \\
\text { Meas.machine: PDS measures }\end{array}$ \\
\hline 23 & Kisseleva et al. (1975) & Pulkovo & Telescope: normal astrograph. \\
\hline 24 & Soulie (1978) & Bordeaux-Floirac & Telescope: $33-\mathrm{cm}$ refrac. \\
\hline 25 & Sinclair $(1974,1977)$ & Herstmonceux & Telescope: 13-inch refrac. \\
\hline 26 & Sinclair $(1974,1977)$ & Herstmonceux & Telescope: 26-inch refrac. \\
\hline 27 & Mulholland et al. (1976) & McDonald Observatory & Telescope: 76-cm reflec. \\
\hline 28 & Soulie (1978) & Bordeaux-Floirac & Telescope: $38-\mathrm{cm}$ refrac. \\
\hline 29 & Gorel (1977) & Nikolaev & Telescope: Zone astrograph \\
\hline 31 & Pascu (1982) priv. comm. & USNO Washington (since 1893) & Telescope -26 inch refrac. \\
\hline 32 & Levitskaya (1979) & Ordubad & $\begin{array}{l}\text { Telescope: lunar-planet telescope, } \\
D=700 \mathrm{~mm}, F=10313 \mathrm{~mm}\end{array}$ \\
\hline 34 & Mulholland \& Shelus (1980) & McDonald Observatory & Telescope - reflec., $D=2.1 \mathrm{~m}$ \\
\hline 35 & Soulie et al. (1981) & Bordeaux-Floirac & Telescope: $33 \mathrm{~cm}$ refrac. \\
\hline 37 & Seitzer \& Ianna (1980) & Leander McCormick Observatory & Telescope: 67 - refrac. \\
\hline 38 & Chugunov (1981) & Engelhardt Observatory & Telescope: 16-inch astrograph \\
\hline 39 & Taylor \& Sinclair (1985) & Herstmonceux & Telescope: 26-inch refrac. \\
\hline 40 & Seitzer et al. (1979) & Leander McCormick Observatory & Telescope: $67 \mathrm{~cm}$-refrac. \\
\hline 41 & Chugunov \& Nefed'ev (1980) & Engelhardt Observatory & Telescope: 16-inch astrograph \\
\hline 42 & Aksnes et al. (1984) & Various & Telescope: $26^{\prime \prime}$ refrac. \\
\hline 43 & Rohde et al. (1982) & Leander McCormick Observatory & Telescope: 67- refrac. \\
\hline 45 & Kitkin \& Chugunov (1980) & Engelhardt Observatory & Telescope: $16^{\prime \prime}$ astrograph \\
\hline 46 & Dourneau et al. (1989) & Bordeaux-Floirac & Telescope: $38 \mathrm{~cm}$ refrac. \\
\hline 47 & Veillet \& Dourneau (1992) & Pic du Midi & Telescope: $1 \mathrm{~m}$ reflec. \\
\hline 48 & Veillet \& Dourneau (1992) & ESO, La Silla & Telescope: $1.5 \mathrm{~m}$ reflec. \\
\hline 49 & Veillet \& Dourneau (1992) & Mauna Kea & Telescope: 3.6 m reflec. \\
\hline 50 & Debehogne (1981, 1982) & ESO, La Silla & Telescope: 40-cm refrac. \\
\hline 51 & Kitkin \& Chugunov (1982) & Engelhardt Observatory & Telescope: $16^{\prime \prime}$ astrograph \\
\hline 52 & Dourneau et al. (1986) & ESO, La Silla & Telescope: $1.5 \mathrm{~m}$ reflec. \\
\hline 53 & Dourneau et al. (1985) & Bordeaux-Floirac & Telescope: $38 \mathrm{~cm}$ reflec. \\
\hline 54 & Bowell (1982) & Lowell Observatory & Telescope: 13-inch refrac. \\
\hline 55 & Debehogne (1984) & ESO, La Silla & Telescope: $40-\mathrm{cm}$ equatorial \\
\hline 56 & Kitkin (1985) & Engelhardt Observatory & Telescope: $16^{\prime \prime}$ astrograph \\
\hline 57 & Kitkin (1985) & Engelhardt Observatory & Telescope: Zeiss astrograph \\
\hline 58 & Kisseleva et al. (1987) & Abastuman & Telescope: Zeiss Double Astrograph \\
\hline 59 & Rapaport (pers communi) & Bordeaux-Floirac & Telescope: Meridian circle \\
\hline 60 & CMC La Palma No4 (1989) & La Palma & Telescope: Carlsberg automatic meridian circle \\
\hline 61 & Shen (pers communi) & Yunnan Observatory & Telescope: $1 \mathrm{~m}$ refrac. \\
\hline & & Harper $\mathcal{E}$ Taylor references & \\
\hline 101 & Barnard (1913) & Yerkes Observatory & 40-inch refrac. \\
\hline 102 & Barnard (1915) & Yerkes Observatory & 40-inch refrac. \\
\hline 103 & Barnard (1916) & Yerkes Observatory & 40-inch refrac. \\
\hline
\end{tabular}


Table 2. continued.

\begin{tabular}{|c|c|c|c|}
\hline Ref. Code & Reference & Observatory & Instrument \\
\hline 104 & Barnard (1918) & Yerkes Observatory & 40-inch refrac. \\
\hline 105 & Barnard (1927) & Yerkes Observatory & 40-inch refrac. \\
\hline 131 & Hussey (1902) & Lick Observatory & 12-inch \& 36-inch refrac.s \\
\hline 132 & Hussey (1903) & Lick Observatory & 12-inch \& 36-inch refrac.s \\
\hline 133 & Hussey (1905) & Lick Observatory & 36-inch refrac. \\
\hline 144 & Lovett (1898a) & Leander McCormick Obs & 26-inch refrac. \\
\hline 145 & Morgan (1898) & Leander McCormick Obs & 26-inch refrac. \\
\hline 147 & Stone (1898a) & Leander McCormick Obs & 26-inch refrac. \\
\hline 148 & Stone $(1898 b)$ & Leander McCormick Obs & 26-inch refrac. \\
\hline 149 & Stone $(1898 \mathrm{c})$ & Leander McCormick Obs & 26-inch refrac. \\
\hline 150 & Stone (1898d) & Leander McCormick Obs & 26-inch refrac. \\
\hline 200 & Barnard (1908) & Yerkes Observatory & 40-inch, 24-inch, 10-inch refrac.s \\
\hline 202 & Aitken (1909) & Lick Observatory & 36-inch refrac. \\
\hline 203 & Aitken (1905) & Lick Observatory & 36-inch refrac. \\
\hline 206 & Barnard (1910) & Yerkes Observatory & 40-inch refrac. (presumedly) \\
\hline 211 & Eastwood (1900) & Leander McCormick Obs & 26-inch refrac. \\
\hline 222 & Lovett (1895) & Leander McCormick Obs & 26-inch refrac. \\
\hline 223 & Lovett (1896) & Leander McCormick Obs & 26-inch refrac. \\
\hline 224 & Lovett (1898b) & Leander McCormick Obs & 26-inch refrac. \\
\hline 225 & Lovett (1897) & Leander McCormick Obs & 26-inch refrac. \\
\hline 226 & Lovett (1898c) & Leander McCormick Obs & 26-inch refrac. \\
\hline 227 & Lyon (1899a) & Leander McCormick Obs & 26-inch refrac. \\
\hline 228 & Lyon (1899b) & Leander McCormick Obs & 26-inch refrac. \\
\hline 232 & Morgan (1897) & Leander McCormick Obs & 26-inch refrac. \\
\hline 233 & Morgan (1900) & Leander McCormick Obs & 26-inch refrac. \\
\hline 235 & Paddock (1905) & Leander McCormick Obs & 26-inch refrac. \\
\hline 240 & Stone (1895a) & Leander McCormick Obs & 26-inch refrac. \\
\hline 241 & Stone $(1895 b)$ & Leander McCormick Obs & 26-inch refrac. \\
\hline 242 & Stone (1896a) & Leander McCormick Obs & 26-inch refrac. \\
\hline 243 & Stone (1896b) & Leander McCormick Obs & 26-inch refrac. \\
\hline & & NSDC references & \\
\hline 420 & Noyelles et al. (2003) best & Various & \\
\hline 421 & Noyelles et al. (2003) acc & Various & \\
\hline 502 & Kostinsky (1925) & Pulkovo & Normalastrograph \\
\hline 504 & Debehogne (1979) & Uccle & Double astrograph, $D=40 \mathrm{~cm}$ \\
\hline 507 & Kiseleva (1989) & Pulkovo & Double astrograph, $F=70 \mathrm{~cm}, D=10 \mathrm{~cm}$ \\
\hline 509 & Izhakevich (1991) & Golosseevo-Kiev & $\begin{array}{l}\text { Double long-focus astrograph, } D=400 \mathrm{~mm}, \\
F=5500 \mathrm{~mm} \text { and Double wide-field astrograph, } \\
D=400 \mathrm{~mm}, F=2000 \mathrm{~mm}\end{array}$ \\
\hline 510 & Tolbin (1991) & Pulkovo & Normal astrograph, $D=33 \mathrm{~cm}, F=3.64 \mathrm{~m}$ \\
\hline 511 & Tolbin (1991) & Pulkovo & \\
\hline 512 & Tolbin (1991) & Pulkovo & refrac., $F=10.4 \mathrm{~m}, D=62 \mathrm{~cm}$ \\
\hline 513 & Kiseleva et al. (1996) & Pulkovo & refrac., $F=10.4 \mathrm{~m}, D=62 \mathrm{~cm}$ \\
\hline 514 & Kiseleva et al. (1996) & Pulkovo & refrac., $F=10.4 \mathrm{~m}, D=62 \mathrm{~cm}$ \\
\hline 516 & Kiseleva et al. (1998) & Pulkovo & refrac., $F=10.4 \mathrm{~m}, D=62 \mathrm{~cm}$ \\
\hline 518 & Vass (1997) & Bucharest & Astrograph, $F=6 \mathrm{~m}, D=38 \mathrm{~cm}$ \\
\hline 519 & Rapaport (2000) priv. comm. & Bordeaux-Floirac & Automatic photoelectric meridian cercle \\
\hline 520 & Veiga et al. (1999) & Itajuba & 1.6 m Ritchey-Chretien reflec. \\
\hline 521 & Harper et al. (1997) & La Palma & 1-metre Jacobus Kapteyn Telescope \\
\hline 522 & Harper et al. (1999) & La Palma & 1-metre Jacobus Kapteyn Telescope \\
\hline 523 & Stone et al. (2000) & USNO, Flagstaff & Flagstaff Astrometric Transit Telescope (FASTT) \\
\hline 524 & Stone et al. (2000) & USNO, Flagstaff & Flagstaff Astrometric Transit Telescope (FASTT) \\
\hline 525 & Kisseleva \& Chanturiya (2000) & Abastuman & Double wide-field astrograph, \\
\hline 529 & Kisseleva \& Kalin. (2000) & Pulkovo & refrac., $F=10.4 \mathrm{~m}, D=62 \mathrm{~cm}$ \\
\hline 530 & Kisseleva \& Izmailov (2000) & Pulkovo & refrac., $F=10.4 \mathrm{~m}, D=62 \mathrm{~cm}$ \\
\hline 531 & Filippov et al. (2001) priv.comm. & Golosseevo-Kiev & $\begin{array}{l}\text { Double long focus astrograpf, } \\
D=400 \mathrm{~mm}, F=5500 \mathrm{~mm}\end{array}$ \\
\hline 532 & Izakevich (2001) priv.comm. & Golosseevo-Kiev & $\begin{array}{l}\text { Double wide-field astrograpf, } \\
D=400 \mathrm{~mm}, F=2000 \mathrm{~mm}\end{array}$ \\
\hline 533 & Belizon et al. (2001) priv.comm. & El Leoncito & $\begin{array}{l}\text { San Fernando Automatic Meridian Circle, } \\
D=18 \mathrm{~cm}\end{array}$ \\
\hline 537 & Voronenko et al. (1991) & Nikolaev & Zonal astrograph, $D=120 \mathrm{~mm}, F=2044 \mathrm{~mm}$ \\
\hline 538 & Voronenko (2001) priv. comm. & Nikolaev & Zonal astrograph, $D=120 \mathrm{~mm}, F=2044 \mathrm{~mm}$ \\
\hline
\end{tabular}


Table 2. continued.

\begin{tabular}{rccl}
\hline \hline Ref. Code & Reference & Observatory & Instrument \\
\hline 539 & Vienne et al. (2001) & Itajuba & Ritchey-Chretien reflec., $D=1.6 \mathrm{~m}, F=15.8 \mathrm{~m}$ \\
540 & Kowalski (2001) priv. comm. & Zephyrhills & Maksutov, $D=0.18 \mathrm{~m}$ \\
541 & Peng et al. (2002) & Yunnan Observatory & reflec., $D=1 \mathrm{~m}$. \\
542 & Kiseleva \& Kalin. (2002) & Pulkovo & refrac., $F=10.4 \mathrm{~m}, D=65 \mathrm{~cm}$ \\
543 & Stone (2001) & USNO, Flagstaff & Flagstaff Astrometric Transit Telescope (FASTT) \\
545 & Veiga et al. (2003) & Itajuba & $1.6 \mathrm{~m}$ Ritchey-Chretien reflec., $F=15.8 \mathrm{~m}$. \\
546 & Hatanaka (1995) & Tokyo-Mitaka & refrac., $D=65 \mathrm{~cm}, F=10 \mathrm{~m}$ \\
547 & Abrahamian et al. (1993) & Byurakan & ZTA, $D=2.6 \mathrm{~m}, F=10 \mathrm{~m}$ \\
548 & Walker et al. (1978) & USNO Washington (since 1893) & Astrograph, $D=38 \mathrm{~cm}$ \\
552 & Carlsberg (1999) & La Palma & Carlsberg Automatic Meridian Circle \\
\hline & & New references & \\
600 & Rapaport (2002) & Bordeaux-Floirac & Bordeaux CCD meridian circle \\
601 & Dourneau (1995-2007) & Bordeaux-Floirac & Bordeaux CCD meridian circle \\
602 & USNO Flagstaff (1999-2006) & USNO, Flagstaff & Flagstaff Astrom. Transit Teles. \\
603 & Qiao et al. (1999) & Zo-Se & $1.56 \mathrm{~m}$ reflec. \\
604 & Qiao et al. (2004) & Zo-Se & $1.56 \mathrm{~m}$ reflec. \\
605 & French (2006) HST PC & Hubble Space Telescope & HST Planetary Camera \\
606 & French (2006) HST WF2 & Hubble Space Telescope & HST Wide Field \\
607 & French (2006) HST WF3 & Hubble Space Telescope & HST Wide Field \\
608 & French (2006) HST WF4 & Hubble Space Telescope & HST Wide Field \\
\hline
\end{tabular}

Table 3. Catalogue used for the astrometric reduction of some references.

\begin{tabular}{|c|c|c|}
\hline Ref. Code & Reference & Catalogue \\
\hline 12 & Soulié \& Pourteau (1968) & SAO \\
\hline 14 & Soulié (1972) & SAO \\
\hline 17 & Soulié (1975) & SAO \\
\hline 24,28 & Soulié (1978) & SAO \\
\hline 35 & Soulié et al. (1981) & SAO \\
\hline 46 & Dourneau et al. (1989) & SAO \\
\hline 47 & Veillet \& Dourneau (1992) & S2-S3-S4-S5-S6 D87 \\
\hline 48 & Veillet \& Dourneau (1992) & SAO \& Perth70 \\
\hline 49 & Veillet \& Dourneau (1992) & AGK3 \& SAO \\
\hline 52 & Dourneau et al. (1986) & AGK3 \\
\hline 53 & Dourneau et al. (1985) & AGK3 (for 1981) \& SAO (for 1982) \\
\hline 509 & Izhakevich (1991) & Catalogue PPM \\
\hline 510 & Tolbin (1991) & Catalogue FK5/FK4 \\
\hline 512 & Tolbin (1991) & Catalogue FK5/FK4 \\
\hline 520 & Veiga et al. (1999) & GSC corrected by PPM \\
\hline 521 & Harper et al. (1997) & S3-S4-S5-S6 HT93 \\
\hline 522 & Harper et al. (1999) & S3-S4-S5-S6 HT93 \\
\hline 523 & Stone $(2000)$ & Catalogue AST \\
\hline 524 & Stone \& Harris (2000) & Catalogue AST \\
\hline 525 & Kisseleva \& Chanturiya(2000) & Catalogue ACT \\
\hline 531 & Filippov et al. (2001) & Catalogue ACT \\
\hline 532 & Izakevich (2001) & Catalogue ACT \\
\hline 533 & Belizon et al. (2001) & 1976 IAU reference system \\
\hline 537 & Voronenko et al.(1991) & Hipparcos/Tycho \& ACTRC \\
\hline 538 & Voronenko (2001) & Hipparcos/Tycho \& ACTRC \\
\hline 539 & Vienne et al. (2001) & S3-S4-S5-S6 TASS1.7 \\
\hline 543 & Stone (2001) & Catalogue - Tycho-2 (ICRF) \\
\hline 545 & Veiga et al. (2003) & S3-S4-S5-S6 TASS1.7 \\
\hline 547 & Abrahamian et al. (1993) & Catalogue FOCAT-S (FK5,J2000) \\
\hline 548 & Walker et al. (1978) & Catalogue $-\mathrm{SAO}$ \\
\hline 552 & Carlsberg (1999) & 1976 IAU reference system \\
\hline 601 & Dourneau et al. (2007) & Catalogue - Tycho-2 (ICRF) \\
\hline 602 & USNO Flagstaff (2000-2007) & Catalogue - Tycho-2 (ICRF) \\
\hline 603 & Qiao et al. (1999) & S3-S4-S5-S6 HT93, TASS1.7, TS88, D87 \\
\hline 604 & Qiao et al. (2004) & S3-S4-S5-S6 TASS1.7 \\
\hline 605 & French et al. (2006) HST PC & Rings \\
\hline 606 & French et al. (2006) HST WF2 & Rings \\
\hline 607 & French et al. (2006) HST WF3 & Rings \\
\hline 608 & French et al. (2006) HST WF4 & Rings \\
\hline
\end{tabular}


Table 4. Extract from catalogue COSS08 with the first and the last observations.

\begin{tabular}{|c|c|c|c|c|c|c|c|c|c|c|c|c|c|c|c|c|c|c|}
\hline 257 & 1874 & 7 & 15.2570840 & -2.881 & 787 & 1 & 3 & 70 & 01 & 0.0000000 & 98.8830000 & 1 & 0 & 999.999 & -1.021 & 2 & 2 & 2 \\
\hline 257 & 1874 & 7 & 15.2640290 & -2.881 & 787 & 1 & 3 & 70 & 10 & 132.2000000 & 0.0000000 & 1 & 0 & 0.719 & 999.999 & 2 & 2 & 2 \\
\hline 257 & 1874 & 8 & 30.1202790 & -2.971 & 787 & 1 & 3 & 50 & 10 & 287.6000000 & 0.0000000 & 1 & 0 & -0.375 & 999.999 & 2 & 2 & 2 \\
\hline 257 & 1874 & 8 & 30.1237510 & -2.971 & 787 & 1 & 3 & 30 & 10 & 299.0000000 & 0.0000000 & 1 & 0 & -0.213 & 999.999 & 2 & 2 & 2 \\
\hline 257 & 1874 & 8 & 30.1279180 & -2.971 & 787 & 1 & 3 & 20 & 10 & 268.3000000 & 0.0000000 & 1 & 0 & 0.317 & 999.999 & 2 & 2 & 2 \\
\hline 257 & 1874 & 8 & 30.1327790 & -2.971 & 787 & 1 & 3 & 40 & 10 & 107.3000000 & 0.0000000 & 1 & 0 & 0.290 & 999.999 & 2 & 2 & 2 \\
\hline 257 & 1874 & 8 & 30.1369460 & -2.971 & 787 & 1 & 3 & 60 & 10 & 185.4000000 & 0.0000000 & 1 & 0 & 0.254 & 999.999 & 2 & 2 & 2 \\
\hline 257 & 1874 & 8 & 30.1438900 & -2.971 & 787 & 1 & 3 & 50 & 01 & 0.0000000 & 66.7010000 & 1 & 0 & 999.999 & -1.493 & 2 & 2 & 2 \\
\hline 257 & 1874 & 8 & 30.1494460 & -2.971 & 787 & 1 & 3 & 30 & 01 & 0.0000000 & 25.4770000 & 1 & 0 & 999.999 & -0.947 & 2 & 2 & 2 \\
\hline 257 & 1874 & 8 & 30.1550010 & -2.971 & 787 & 1 & 3 & 20 & 01 & 0.0000000 & 33.2860000 & 1 & 0 & 999.999 & -0.840 & 2 & 2 & 2 \\
\hline 385 & 2007 & 4 & 15.8272500 & 65.184 & 999 & 601 & 0 & $8 *$ & 11 & 140.7682387 & 16.6673253 & 2 & 0 & 0.005 & 0.048 & 1 & 1 & 2 \\
\hline 385 & 2007 & 4 & 15.8275220 & 65.184 & 999 & 601 & 0 & $7 *$ & 11 & 140.8665154 & 16.6499964 & 2 & 0 & 0.235 & -0.280 & 1 & 1 & 2 \\
\hline 385 & 2007 & 4 & 15.8275930 & 65.184 & 999 & 601 & 0 & $6 *$ & 11 & 140.8923746 & 16.6512411 & 2 & 0 & 0.015 & -0.066 & 1 & 1 & 2 \\
\hline 385 & 2007 & 4 & 18.1296759 & 65.184 & 689 & 602 & 0 & $4 *$ & 11 & 140.8983800 & 16.6686028 & 2 & 1 & -0.093 & -0.046 & 1 & 1 & 1 \\
\hline 385 & 2007 & 4 & 18.1296759 & 65.184 & 689 & 602 & 0 & $5^{*}$ & 11 & 140.8896617 & 16.6663225 & 2 & 1 & 0.093 & 0.046 & 1 & 1 & 1 \\
\hline 385 & 2007 & 4 & 18.1296759 & 65.184 & 689 & 602 & 0 & 7* & 11 & 140.8891479 & 16.6496936 & 2 & 1 & 0.384 & -0.173 & 1 & 1 & 1 \\
\hline 385 & 2007 & 4 & 18.1296759 & 65.184 & 689 & 602 & 0 & 8* & 11 & 140.7625637 & 16.6683714 & 2 & 1 & -0.014 & -0.055 & 1 & 1 & 1 \\
\hline 385 & 2007 & 4 & 18.1312072 & 65.184 & 689 & 602 & 0 & $6^{*}$ & 11 & 140.9259692 & 16.6552381 & 2 & 1 & -0.072 & -0.225 & 1 & 1 & 1 \\
\hline
\end{tabular}

Note that the heliocentric reference frame $(r f r=2)$ is only used for mutual phenomena, especially for eclipse observations.

Oppositions have been numbered since 1610 (first observations of satellites by Galileo Galilei). So, observations of COSS08 are from opposition 257 in 1874 to opposition 385 in 2007.

The main modifications compared to the ST90 catalogue are the parameters added like refraction, aberration and phase effect corrections, and the unification of the time scale.

The O-C residuals have been computed with the TASS1.7 model (Duriez \& Vienne 1997, for Hyperion motion and Vienne \& Duriez 1994, for the seven others) according to the correction of refraction, aberration and phase effects. The position of Saturn is given by numerical ephemeris DE414, from JPL (Standish 2006). Residuals are purely indicative to measure the accuracy of observations in relation to the TASS model. When it was possible, residuals have been computed in intersatellite coordinates. For example, if satellites have been observed at the same moment and expressed in absolute coordinates or compared to the planet, $\mathrm{O}-\mathrm{C}$ values were been computed in intersatellite coordinates compared to a reference satellite. In such a case, the reference satellite is indicated with the parameter satref.

\subsection{Distribution of observations}

In counting the observations, we adopt the same method as ST90. We have taken each coordinate for each observed or reference satellite. For example, if both coordinates of EnceladeTitan have been given, two observations for Encelade and two observations of Titan have been counted. This means that for one line of COSS08, we could have one, two or four observations. However if the same reference satellite appears several times in intersatellite measurements on a photographic plate, it is counted only once. Histograms of the number of observations at each opposition from 1874 to 2007 are represented in Fig. 1. The distribution is relatively inhomogeneous. There are significant gaps between 1930 and 1938 and between 1947 and 1961 . Nevertheless there are also years with many observations. Indeed in 1995, there are more than 28000 observations. In 1995, mutual phenomena of Saturn's satellites were observed with CCD cameras. Just before and after these phenomena, satellites were observed and their positions were reduced. Because of this inhomogeneity, we present histograms of the number of observation nights at each opposition in Fig. 2. The details of each satellite can be found in Fig. 3 .

Table 1 gives the number of observations and the period covered for each satellite. Differences can be observed between satellites. Mimas and Enceladus are less observed because of their closeness to Saturn. Hyperion is a faint body and its observation was particulary difficult in the past. Iapetus is not much observed because with CCD images, the field of view is often small and the satellite is often out of this field. However, Rhea, Titan, Dione and Tethys are highly observed satellites. The total of observations represents 130898 observations (over 6023 nights).

\subsection{Statistics of observations}

We present in Table 5 the statistics of residuals for the ten references with numerous observations. First, the name and the Ref. Code of the reference, and the type of coordinates are indicated. Secondly, we give astrometric observation residuals for each type and each satellite ${ }^{5} . \mu_{\alpha}, \sigma_{\alpha}$ and $N_{\alpha}$ represent the mean, the standard deviation and the number of residuals of the first coordinate. $\mu_{\delta}, \sigma_{\delta}$ and $N_{\delta}$ are for the second coordinate. All the observations with $\mathrm{O}-\mathrm{C}$ value larger than $2^{\prime \prime}$ were rejected for the residual computation.

\section{Conclusion}

The COSS08 catalogue is composed of more than 130000 observations of the eight major satellites of Saturn. All observations are in the same consistent format. This catalogue can be very useful to fit a dynamical model by comparison to observations. Also, information about reduction is given and allows this comparison.

The large period covered by COSS08 from 1874 to 2007 allows the detection of long-term perturbations in the satellite motion. Thus, the tidal effects, measurable through a detection of an acceleration of the satellites, may be detected (Lainey et al. 2007).

\footnotetext{
5 S1 means Mimas, S2 Enceladus, S3 Tethys, S4 Dione, S5 Rhea, S6 Titan, S7 Hyperion and S8 Iapetus.
} 
Table 5. Statistics for the ten most numerous observation references.

\begin{tabular}{|c|c|c|c|c|c|c|c|}
\hline Reference & Satellite & $\mu_{\alpha}$ & $\sigma_{\alpha}$ & $\mu_{\delta}$ & $\sigma_{\delta}$ & $\overline{N_{\alpha}}$ & $N_{\delta}$ \\
\hline Vienne et al. (2001) & S1 & -0.016 & 0.083 & 0.001 & 0.078 & 216 & 216 \\
\hline 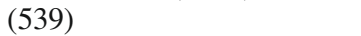 & $\mathrm{S} 2$ & 0.014 & 0.092 & -0.006 & 0.067 & 861 & 861 \\
\hline \multirow[t]{6}{*}{$(\Delta \alpha \cos \delta, \Delta \delta)$} & S3 & 0.004 & 0.080 & 0.003 & 0.065 & 2048 & 2048 \\
\hline & S4 & -0.007 & 0.062 & 0.000 & 0.055 & 1570 & 1570 \\
\hline & S5 & 0.014 & 0.084 & -0.002 & 0.063 & 4739 & 4739 \\
\hline & S6 & 0.007 & 0.106 & 0.009 & 0.087 & 1484 & 1484 \\
\hline & S7 & -0.084 & 0.118 & -0.038 & 0.121 & 322 & 322 \\
\hline & S8 & -0.107 & 0.090 & 0.010 & 0.068 & 524 & 524 \\
\hline \multirow{8}{*}{$\begin{array}{l}\text { USNO Flagstaff 1999-2006 } \\
(602) \\
(\alpha, \delta)\end{array}$} & S1 & 0.000 & 0.000 & 0.000 & 0.000 & 0 & 0 \\
\hline & $\mathrm{S} 2$ & 0.000 & 0.000 & 0.000 & 0.000 & 0 & 0 \\
\hline & S3 & -0.040 & 0.172 & 0.011 & 0.139 & 116 & 116 \\
\hline & S4 & 0.006 & 0.105 & -0.011 & 0.130 & 203 & 203 \\
\hline & S5 & 0.016 & 0.090 & 0.004 & 0.117 & 364 & 364 \\
\hline & S6 & 0.068 & 0.115 & -0.038 & 0.112 & 405 & 405 \\
\hline & S7 & -0.005 & 0.259 & 0.050 & 0.321 & 300 & 300 \\
\hline & S8 & -0.012 & 0.105 & -0.010 & 0.137 & 353 & 353 \\
\hline \multirow{8}{*}{$\begin{array}{l}\text { Pascu (1982) priv. comm. } \\
(31) \\
(\Delta \alpha \cos \delta, \Delta \delta)\end{array}$} & S1 & -0.055 & 0.223 & -0.017 & 0.157 & 57 & 57 \\
\hline & $\mathrm{S} 2$ & -0.009 & 0.125 & -0.022 & 0.157 & 110 & 110 \\
\hline & S3 & -0.003 & 0.074 & -0.003 & 0.099 & 140 & 140 \\
\hline & S4 & -0.012 & 0.066 & 0.003 & 0.108 & 166 & 167 \\
\hline & S5 & 0.013 & 0.064 & -0.023 & 0.079 & 209 & 209 \\
\hline & S6 & -0.011 & 0.066 & 0.024 & 0.081 & 228 & 228 \\
\hline & S7 & 0.050 & 0.236 & -0.075 & 0.171 & 11 & 11 \\
\hline & S8 & -0.028 & 0.146 & 0.033 & 0.145 & 217 & 216 \\
\hline \multirow{8}{*}{$\begin{array}{l}\text { USNO (1929) } \\
(4) \\
(p, s)\end{array}$} & S1 & -0.002 & 0.198 & -0.083 & 0.221 & 122 & 121 \\
\hline & $\mathrm{S} 2$ & -0.006 & 0.169 & -0.080 & 0.167 & 129 & 127 \\
\hline & S3 & -0.008 & 0.169 & -0.002 & 0.185 & 487 & 483 \\
\hline & S4 & 0.006 & 0.159 & -0.006 & 0.166 & 280 & 281 \\
\hline & S5 & 0.008 & 0.154 & -0.031 & 0.198 & 694 & 690 \\
\hline & S6 & -0.002 & 0.214 & 0.025 & 0.274 & 581 & 575 \\
\hline & S7 & -0.010 & 0.380 & 0.128 & 0.468 & 89 & 88 \\
\hline & S8 & -0.004 & 0.210 & 0.158 & 0.169 & 120 & 117 \\
\hline \multirow{8}{*}{$\begin{array}{l}\text { Harper et al. (1999) } \\
(522) \\
(\Delta \alpha \cos \delta, \Delta \delta)\end{array}$} & S1 & 0.172 & 0.234 & -0.064 & 0.099 & 14 & 15 \\
\hline & S2 & -0.081 & 0.600 & -0.056 & 0.241 & 118 & 119 \\
\hline & S3 & -0.017 & 0.093 & -0.003 & 0.099 & 277 & 277 \\
\hline & S4 & 0.015 & 0.087 & -0.005 & 0.112 & 219 & 219 \\
\hline & S5 & -0.004 & 0.238 & -0.012 & 0.188 & 1068 & 1068 \\
\hline & S6 & 0.065 & 0.146 & -0.030 & 0.112 & 336 & 336 \\
\hline & S7 & 0.103 & 0.222 & 0.056 & 0.326 & 189 & 187 \\
\hline & S8 & -0.148 & 0.123 & 0.118 & 0.107 & 189 & 189 \\
\hline \multirow{8}{*}{$\begin{array}{l}\text { Qiao et al. } 2004 \\
(604) \\
(\Delta \alpha \cos \delta, \Delta \delta)\end{array}$} & S1 & 0.040 & 0.255 & 0.062 & 0.136 & 44 & 44 \\
\hline & S2 & -0.081 & 0.185 & 0.063 & 0.248 & 141 & 141 \\
\hline & S3 & 0.008 & 0.126 & -0.002 & 0.154 & 236 & 236 \\
\hline & S4 & -0.018 & 0.090 & 0.028 & 0.105 & 246 & 246 \\
\hline & S5 & 0.020 & 0.132 & -0.003 & 0.148 & 862 & 862 \\
\hline & S6 & 0.002 & 0.099 & -0.038 & 0.120 & 241 & 241 \\
\hline & S7 & 0.000 & 0.000 & 0.000 & 0.000 & 0 & 0 \\
\hline & S8 & -0.090 & 0.075 & -0.100 & 0.075 & 66 & 66 \\
\hline \multirow{8}{*}{$\begin{array}{l}\text { Harper et al. (1997) } \\
(521) \\
(\Delta \alpha \cos \delta, \Delta \delta)\end{array}$} & S1 & -0.160 & 0.213 & 0.050 & 0.213 & 73 & 73 \\
\hline & S2 & -0.022 & 0.109 & -0.007 & 0.163 & 199 & 199 \\
\hline & S3 & -0.011 & 0.079 & -0.002 & 0.089 & 221 & 221 \\
\hline & S4 & 0.003 & 0.072 & 0.000 & 0.079 & 214 & 214 \\
\hline & S5 & 0.023 & 0.118 & -0.006 & 0.129 & 852 & 852 \\
\hline & S6 & -0.015 & 0.087 & 0.009 & 0.096 & 157 & 157 \\
\hline & S7 & 0.043 & 0.203 & 0.043 & 0.144 & 88 & 88 \\
\hline & S8 & -0.066 & 0.072 & -0.030 & 0.085 & 52 & 52 \\
\hline \multirow{8}{*}{$\begin{array}{l}\text { Struve (1898) } \\
(9) \\
(p, s)\end{array}$} & S1 & 0.030 & 0.181 & 0.012 & 0.163 & 119 & 105 \\
\hline & S2 & -0.032 & 0.121 & 0.003 & 0.126 & 233 & 222 \\
\hline & S3 & -0.005 & 0.124 & 0.034 & 0.131 & 549 & 532 \\
\hline & S4 & -0.032 & 0.136 & 0.065 & 0.144 & 212 & 209 \\
\hline & S5 & 0.026 & 0.127 & -0.073 & 0.143 & 490 & 475 \\
\hline & S6 & -0.069 & 0.345 & 0.034 & 0.281 & 80 & 78 \\
\hline & S7 & 0.059 & 0.603 & -0.038 & 0.336 & 232 & 234 \\
\hline & S8 & -0.054 & 0.319 & -0.027 & 0.209 & 22 & 22 \\
\hline
\end{tabular}


Table 5. continued.

\begin{tabular}{|c|c|c|c|c|c|c|c|}
\hline Reference & Satellite & $\mu_{\alpha}$ & $\sigma_{\alpha}$ & $\mu_{\delta}$ & $\sigma_{\delta}$ & $\overline{N_{\alpha}}$ & $\overline{N_{\delta}}$ \\
\hline Veillet \& Dourneau 1.5 & S1 & -0.205 & 0.156 & -0.047 & 0.105 & 10 & 10 \\
\hline$(48)$ & S2 & -0.004 & 0.124 & -0.025 & 0.120 & 57 & 57 \\
\hline \multirow[t]{6}{*}{$(\Delta \alpha \cos \delta, \Delta \delta)$} & S3 & -0.003 & 0.139 & 0.012 & 0.093 & 78 & 78 \\
\hline & S4 & 0.008 & 0.083 & 0.003 & 0.082 & 155 & 155 \\
\hline & S5 & -0.010 & 0.125 & -0.007 & 0.098 & 884 & 884 \\
\hline & S6 & -0.004 & 0.092 & 0.021 & 0.076 & 199 & 199 \\
\hline & S7 & 0.006 & 0.168 & 0.008 & 0.089 & 197 & 197 \\
\hline & S8 & 0.051 & 0.116 & 0.003 & 0.126 & 196 & 196 \\
\hline \multirow{8}{*}{$\begin{array}{l}\text { Peng et al. (2002) } \\
(541) \\
(\Delta \alpha \cos \delta, \Delta \delta)\end{array}$} & S1 & -0.023 & 0.054 & -0.017 & 0.044 & 54 & 54 \\
\hline & S2 & -0.005 & 0.051 & -0.021 & 0.054 & 136 & 136 \\
\hline & S3 & 0.000 & 0.034 & -0.002 & 0.043 & 120 & 120 \\
\hline & S4 & -0.004 & 0.037 & -0.002 & 0.038 & 136 & 136 \\
\hline & S5 & 0.029 & 0.066 & 0.023 & 0.047 & 336 & 336 \\
\hline & S6 & 0.006 & 0.051 & -0.003 & 0.061 & 548 & 548 \\
\hline & S7 & -0.022 & 0.066 & 0.037 & 0.095 & 96 & 96 \\
\hline & S8 & -0.083 & 0.073 & -0.050 & 0.043 & 102 & 102 \\
\hline
\end{tabular}

Ground-based observations remain very useful for the improvement of the knowledge of satellite motion. We encourage future observers to publish their data in the COSS08 format and to indicate the frame center positions with their data, because it will allow us to use tangential coordinates in the astrometric reduction and consequently, in some cases it will improve the accuracy of the derived observed positions of satellites.

Acknowledgements. We would like to thank R. V. Martins for his participation in collecting data. We also thank N. Emelianov for his help and the update of NSDC observations. We are very grateful to V. Lainey for many helpful discussions. We wish to thank G. Dourneau for a careful reading of the manuscript and valuable comments that greatly helped to improve the present work. The catalogue is also available on the web server of the IMCCE at ftp://ftp.imcce.fr/pub/databases/NSDC/saturn/raw data/position/1874-2007_S1-8_COSS08.data.txt

\section{References}

Abbot, R. I., Mulholland, J. D., \& Shelus, P. J. 1975, AJ, 80, 723

Abrahamian, H. V., Gigoian, K., Kisselev, A. A., \& Kisseleva, T. P. 1993, A\&AS Trans., 3, 279

Aitken, R. G. 1905, Lick Obs. Bul., 94

Aitken, R. G. 1909, Lick Obs. Bul., 172

Aksnes, K., Franklin, F., Millis, R., et al. 1984, AJ, 89, 280

Aksnes, K., Franklin, F., \& Magnusson, P. 1986, AJ, 92, 1436

Alden, H. L. 1929, AJ, 40, 88

Alden, H. L., \& O'Connell, W. C. 1928, AJ, 38, 53

Barnard, E. E. 1908, Astron. Nachr., 177, 147

Barnard, E. E. 1910, AJ, 26, 79

Barnard, E. E. 1912, AJ, 27, 116

Barnard, E. E. 1913, AJ, 28, 1

Barnard, E. E. 1915, AJ, 29, 33

Barnard, E. E. 1916, AJ, 30, 33

Barnard, E. E. 1918, AJ, 31, 49

Barnard, E. E. 1927, AJ, 37, 157

Belizon, et al. 2001, private communication

Bowell, E. 1982, IAU Circ., 3719

Carlsberg Meridian Catalogs La Palma 1999, VizieR On-line Data Catalog Chernykh, L. I., \& Chernykh, N. S. 1971, Byull. Inst. Teoret. Astron., 12, 739 Chugunov, I. G. 1981, Izv. Astron. Engelhardt Obs., 47, 111

Chugunov, I. G., \& Nefed'ev, Yu. A. 1980, Astron. Tsirk., 1114, 7

Debehogne, H. 1979, Bulletin Astronomique, 9, 68

Debehogne, H. 1981, IAU Circ., 3654

Debehogne, H. 1982, IAU Circ., 3707

Debehogne, H. 1984, Bulletin Astronomique, 9, 299

Dourneau, G. 1987, Thèse de doctorat d'État, Université de Bordeaux I

Dourneau, G., Dulou, M. R., \& Le Campion, J. F. 1985, A\&A, 142, 91

Dourneau, G., Veillet, C., Dulou, M. R., \& Le Campion, J. F. 1986, A\&A, 160, 280

Dourneau, G., Le Campion, J. F., \& Dulou, M. R. 1989, AJ, 98, 716

Dourneau, G., Le Campion, J. F., Rapaport, M., et al. 2007, Notes Scientifiques et Techniques de l'Institut de Mécanique Céleste, S089
Duriez, L., \& Vienne, A. 1997, A\&A, 324, 366

Emelianov, N., \& Arlot, J. E. 2005, BAAS, 37, 728

Eastwood, E. O. 1900, AJ, 20, 142

Filippov, Yu. K., Herz, E. A., Ledovskaya, I. V., et al. 2001, private communication

French, R. G., McGhee, C. A., Frey, M., et al. 2006, PASP, 118, 246

Gorel, G. K. 1977, Glav. Astron. Obs. Pulkovo, Nicolaev, 10

Harper, D., \& Taylor, D. B. 1993, A\&A, 268, 326

Harper, D., \& Taylor, D. B. 1994, A\&AS, 284, 619

Harper, D., Murray, C. D., Beurle, K., et al. 1997, A\&AS, 121, 65

Harper, D., Beurle, K., Williams, I. P., et al. 1999, A\&AS, 136, 257

Hatanaka, Y. 1995, PNAOJ, 4, 23

Hussey, W. J. 1902, Lick Obs. Bul., 17

Hussey, W. J. 1903, Lick Obs. Bul., 34

Hussey, W. J. 1905, Lick Obs. Bul., 68

Izhakevich, E. M. 1991, Scientific paper deposited in All-russian institute of scientific and technical information, 4553-B91, 1

Izakevich, E. M., \& Sereda, E. M. 2001, private communication

Izmailov, I. S., Kisselev, A. A., Kisseleva, T. P., \& Khrutskaya, E. V. 1998, Astron. Lett., 24, 665

Kisseleva, T. P., \& Kalinitchenko, O. A. 1998, Pulkovo, Glavnaia Astronomicheskaia Observatoriia, Izvestiia, 213, 122

Kisseleva, T. P., \& Chanturiya, S. M. 2000, Pulkovo, Glavnaia Astronomicheskaia Observatoriia, Izvestiia, 214, 356

Kisseleva, T. P., \& Izmailov, I. S. 2000, Pulkovo, Glavnaia Astronomicheskaia Observatoriia, Izvestiia, 214, 333

Kisseleva, T. P., \& Kalinitchenko, O. A. 2000, Pulkovo, Glavnaia Astronomicheskaia Observatoriia, Izvestiia, 214, 344

Kisseleva, T. P., \& Kalinitchenko, O. A. 2002, Pulkovo, Glavnaia Astronomicheskaia Observatoriia, Izvestiia, 216, 185

Kiseleva, T. P., Narizhnaia, N. V., Orlova, O. N., \& Shakht, N. A. 1989, Pulkovo, Glavn. Astronomicheskaia Obs., Izvestiia, ISSN 0367-7966, 206, 12

Kisseleva, T. P., Koroleva, L. S., \& Panova, G. V. 1975, Byull. Inst. Teoret. Astron., 14, 60

Kisseleva, T. P., Panova, G. V., \& Kalinichenko, O. A. 1977, Iz. Glav. Astron. Obs. Pulkovo, 195, 49

Kisseleva, T. P., Chanturiya, S. M., Lepeshenkova, S. A., et al. 1987, Abastumanskaia Astrofizicheskaia Obs., 62, 117

Kisseleva, T. P., Kisselev, A. A., Khrutskaya, E. V., \& Kalinitchenko, O. A. 1996, Pulkovo, Glavnaia Astronomicheskaia Observatoriia, Izvestiia, 210, 76

Kitkin, V. N. 1985, Observations of Saturn's satellites made at the Engelhardt Astronomical Observatory and the Zelenchukskaya Astonomical Station in 1982-1984, Kazan Univ., Kazan, 10

Kitkin, V. N., \& Chugunov, I. G. 1980, Photographic observations of Saturn's satellites at the Engelhardt Astronomical Observatory in January-May, Mordovsk Univ. Sarank, 12

Kitkin, V. N., \& Chugunov, I. G. 1981, Photographic observations of Saturn's satellites at the Engelhardt Astronomical Observatory in 1981, Mordovsk Univ. Sarank, 6

Kostinsky, S. 1925, Astron. Nachr., 226, 67

Kowalski, R. A. 2001, private communication

Lainey, V., Desmars, J., Arlot, J.-E., et al. 2007, AGU Fall Meeting

Levitskaya, T. I. 1979, Astron. Tsirk., 1084, 6

Lindegren, L. 1977, A\&A, 57, 55 
Lovett, E. O. 1895, AJ, 15, 166

Lovett, E. O. 1896, AJ, 16, 63

Lovett, E. O. 1897, Astron. Nachr., 143, 291

Lovett, E. O. 1898a, AJ, 18, 177

Lovett, E. O. 1898b, AJ, 18, 143

Lovett, E. O. 1898c, Astron. Nachr., 145, 347

Lyon, J. A. 1899a, AJ, 19, 185

Lyon, J. A. 1899b, AJ, 20, 105

Morgan, H. R. 1897, AJ, 18, 69

Morgan, H. R. 1898, AJ, 19, 117

Morgan, H. R. 1900, Astron. Nachr., 154, 91

Mulholland, J. D., \& Shelus, P. J. 1980, AJ, 85, 1112

Mulholland, J. D., Shelus, P. J., \& Abbot, R. I. 1976, AJ, 81, 1007

Noyelles, B., Vienne, A., \& Descamps, P. 2003, A\&A, 401, 1159

Paddock, G. F. 1905, AJ, 25, 33

Pascu, D. 1982, private communication

Peng, Q., Vienne, A., \& Shen, K. X. 2002, A\&A, 383, 296

Peters, C. F. 1973, AJ, 78, 957

Pierce, D. A. 1975 , PASP, 87,785

Poulkovo (tables de réfraction de): 1985, Observatoire astronomique principal de l'Académie des sciences d'URSS, Poulkovo (éditions Naouka, section de Léningrad)

Qiao, R. C., Shen, K. X., Liu, J. R., \& Harper, D. 1999, A\&AS, 137, 1

Qiao, R. C., Shen, K. X., Harper, D., \& Liu, J. R. 2004, A\&A, 422, 377

Rapaport, M. 2000, private communication

Rapaport, M., Teixeira, R., Le Campion, J. F., et al. 2002, A\&A, 383, 1054

Rohde, J. R., Ianna, P. A., Stayton, L. C., \& Levinson, F. H. 1982, AJ87, 698

Seitzer, P.. \& Ianna, P. A. 1980, AJ, 85, 1117

Seitzer, P., Ianna, P. A., \& Levinson, F. 1979, AJ, 84, 877

Sinclair, A. T. 1974, MNRAS, 169,591

Sinclair, A. T. 1977, MNRAS, 180, 447

Soulié, G. 1972, A\&AS, 6, 311

Soulié, G. 1975, A\&AS, 22, 49

Soulié, G. 1978, A\&AS, 33, 257

Soulié, G., \& Pourteau, L., 1968, Journal des Observateurs, 51, 315

Soulié, G., Dupouy, Teulet, Broqua, Dulou, M. R. 1981, A\&AS, 43, 147

Standish, E. M. 2006, JPL Planetary Ephemeris DE414, available at ftp:// ssd.jpl.nasa.gov/pub/eph/planets/ioms/de414iom.pdf

Stephenson, F. R., \& Morrison, L. V. 1984, Philos. Trans. Roy. Soc. London, Ser. A, 313, 47

Stone, O. 1895a, AJ, 15, 86

Stone, O. 1895b, AJ, 15, 110

Stone, O. 1896a, AJ, 16, 62

Stone, O. 1896b, AJ, 16, 180

Stone, O. 1898a, Astron. Nachr., 146, 223

Stone, O. 1898b, AJ, 19, 118

Stone, O. 1899a, Astron. Nachr., 148, 201
Stone, O. 1899b, Astron. Nachr., 151, 107

Stone, R. C. 2000 , AJ, 120, 2124

Stone, R. C. 2001, AJ, 122, 2723

Stone, R. C., \& Harris, F. H. 2000, AJ, 119, 1985

Strugnell, P. R., \& Taylor, D. B. 1990, A\&AS, 83, 289

Struve, G. 1933, Veroff. Berlin-Babelsberg 6, parts 2, 3 and 5

Struve, H. 1898, Publ. Obs. Central Nicolas, 11, series 2

Taylor, D. B., \& Sinclair, A. T. 1985, A\&AS, 61, 221

Taylor, D. B., \& Shen, K. X. 1988, A\&A, 200, 269

Tolbin, S. B. 1991, Scientific paper deposited in All-Russian institute of scientific and technical information 3077-B91, 1

Tolbin, S. B. 1991, Scientific paper deposited in All-Russian institute of scientific and technical information 3078-B91, 1

USNO 1877-1887, Astronomical and meteorological observations made during the year ... at the U.S. Naval Observatory

USNO 1887 and 1889-1893, Observations made during the year $\ldots$ at the U.S. Naval Observatory

USNO 1911, Publ. U.S. Naval Obs., 6, Series 2

USNO 1929, Publ. U.S. Naval Obs., 12, Series 2

USNO 1954, Publ. U.S. Naval Obs., 17, Series 2

USNO, Flagstaff available at the adress http://www. nofs navy.mil/data/ plansat.html

Vass, G. 1997, Romanian Astron. J., 7, 45

Veiga, C. H., \& Vieira Martins, R. 1999, A\&AS, 139, 305

Veiga, C. H., Vieira Martins, R., Vienne, A., Thuillot, W., \& Arlot, J. E. 2003, A\&A, 400, 1095

Veillet, C., \& Dourneau, G. 1992, A\&AS, 94, 291

Vienne, A., \& Duriez, L. 1994, A\&A, 297, 588

Vienne, A., Thuillot, W., Veiga, C. H., Arlot, J. E., \& Vieira Martins, R. 2001, A\&A, 380, 727

Vienne, A., Thuillot, W., \& Arlot, J. E. 2001, Notes Scientifiques et Techniques de l'Institut de Mécanique Céleste, S077, 727

Voronenko, V. I., \& Gorel, G. K. 1982, Glav. Astron. Obs. Akad. Nauk. Leningrad, 16

Voronenko, V. I., \& Gorel, G. K. 1986, Glav. Astron. Obs. Akad. Nauk. Leningrad, 92

Voronenko, V. I., \& Gorel, G. K. 1988, Scientific paper deposited in All-Russian institute of scientific and technical information 6693-B88, 1

Voronenko, V. I., Gorel, G. K., Gudkova, L. A., \& Pozhalova, J. A. 1991, Scientific paper deposited in All-Russian institute of scientific and technical information 3167-B91, 1

Voronenko, V. I., Gorel, G. K., Gudkova, L. A., \& Pozhalova, J. A. 2001, private communication

Walker, R. L., Christy, J. W., \& Harrington, R. S. 1978, AJ, 83, 838

Woolard, E. W., \& Clemence, G. M. 1966, Spherical astronomy (New York: Academic Press) 